\title{
An Investigation of Coat Colour Distribution of West African Dwarf Goats
}

\author{
Peter Ayodeji Idowu ${ }^{1} \&$ Olusesan Adeyemi Adelabu ${ }^{2}$ \\ ${ }^{1}$ Department of Livestock and Pasture Science, University of Fort Hare, Alice, Eastern Cape, South Africa \\ ${ }^{2}$ Department of Microbiology and Biochemistry, University of Fort Hare, Alice, Eastern Cape, South Africa \\ Correspondence: Peter Ayodeji Idowu, Department of Livestock and Pasture Science, University of Fort Hare, \\ Alice, Private Bag X1314, Eastern Cape, 5700, South Africa. E-mail: ayodejiidowuolu@gmail.com
}

Received: November 1, 2017

Accepted: January 25, 2018

Online Published: February 15, 2018

doi:10.5539/jas.v10n3p228

URL: https://doi.org/10.5539/jas.v10n3p228

\begin{abstract}
This study was carried out to determine coat colour distribution of West African Dwarf (WAD) goat in Abeokuta North and South Local Government Areas of Ogun State, Nigeria. Three thousand, three hundred and ten (3310) WAD goats were randomly sampled consisting of 2511 (75.86\%) does and $799(24.14 \%)$ bucks. Animals were prevalently maintained on semi-intensive management. Various coat colours identified were black with highest frequency of 941 (28.42\%), brown $436(13.17 \%)$, badgerface $346(10.45 \%)$, grey $254(7.67 \%)$, buckskin 222 $(6.70 \%)$, lateral belly $154(4.65 \%)$, white and black $149(4.50 \%)$, white and brown $134(4.05 \%)$, white and black marking $105(3.17 \%)$, black and white marking $92(2.78 \%)$, spotted white $88(2.66 \%)$, spotted black $80(2.42 \%)$, blackmash $63(1.90 \%)$, tan 61 (1.84\%), white $57(1.72 \%)$, bezoar 49 (1.48\%), spotted brown $40(1.21 \%)$, lateral stripes $33(1.00 \%)$, with swiss marking having the lowest frequency of $6(0.18 \%)$. The gene frequency was estimated using Hardy-Weinberg equilibrium equation which resulted as 0.70 and 0.30 for eumelanin and Phaeomelanin respectively. Chi-square $\left(\chi^{2}\right)$ analysis was further carried out, which revealed that the difference between observed frequency and expected frequency was significant $(\mathrm{P}<0.05)$ implying that the segregation in the area of study was not supported by Mendelian ratio of 3:1. High level of variation was observed in coat colour among goats in the areas studied with black coat colour being the predominant. Hence, conscious selection could be embarked upon to investigate the influence of coat colour on adaptation, thermoregulation, growth and productivity.
\end{abstract}

Keywords: dwarf goat, West African, genetic control, coat colour, locus

\section{Introduction}

Goat has proved particularly useful to man throughout the ages, largely because of their adaptability to the varying environment condition and the different nutritional regimes under which the respective breed and types have been subsequently maintained (Mannetje, 2003). Variation in the body size is one of the criteria used in classifying breeds of goats (Fajemilehin et al., 2008). The three main breed of goat recognized in Nigeria include: The West African Dwarf Goat (WAD) Sokoto Red and West African long legged goat or the Sahel.

The West African Dwarf (WAD) goat is widely distributed across the rain forest belt of Southern Nigeria. They are short legged and small bodied animals (Mourad et al., 2000), and most especially found in rural areas (Oni, 2002). They are hardy, early maturing, prolific and non seasonal breeder (Osuagwuh et al., 1981). They are well adapted and able to withstand the prevalent trypanosome attack in this zone (Rege et al., 1994). The ears are short and erect and point forwards. WAD goat is a preferred meat animal but milk production is poor (Opara et al., 2010). The male stands $22 \mathrm{~mm}$ at the wither and weigh $18 \mathrm{~kg}$ at maturity, whereas the female stands $18 \mathrm{~mm}$ and weigh $15 \mathrm{~kg}$ at maturity (Opara et al., 2010). The abundance of WAD goats in the tropical humid areas of the West African coastal and hinterland areas reflects a better adaptation of this species to these environments when compared to sheep which are found in Nigeria and elsewhere (Epstein, 1953). Nevertheless, recent works have shown that Nigerian WAD goats are endowed with the capacity to resist trypanosome and intestinal nematode infections more than any other breed of goats (Chiejina \& Behnke, 2011).

It is believed that coat colour and certain characteristics provide this breed with unique abilities. Coat colour is very amiable and irregular including black and brown, pied and mixed colour (Adedeji, 2012). It is influenced by 
a large number of genes that are involved in determining the presence, distribution and biochemical activities of the melanocytes (Bennett et al., 2003; Fontanesi et al., 2011). It has a highly repeatable and heritable (53\%) trait. It is majorly controlled by alleles on three loci (A, B and S) although genes on the extension locus (E) tend to modify the effect of these alleles (Klungland et al., 2000). In the same manner, the black coat colour may predispose the goat to high heat load, high metabolic rate and increased thyroid activity as reported by Odubote (1994). Coat colour has fascinated animal breeders and geneticists for years. Classic breeding experiments told us much about the inheritance of coat colours and patterns in the early to mid-nineties (Schmutz et al., 2007). Coat colour and type is known to adapt animals to different climatic zones and has a considerable influence on the performance of various stocks (Odubote, 1994; Okpeku et al., 2011). Mammals coat colour depends basically on the amount of two pigments: eumelanin, which is always black or brown, and pheomelanin which appears yellow or red (Bozgo et al., 2012). The two pigments are controlled by both the Extension (E) and the Agouti (A) loci. According to Bemji et al. (2012), goats can have many different patterns of white spotting, and each of these is totally independent in terms of genetic control.

Observably, approximately $94 \%$ of the world goat population is found in the developing countries. Of this, the largest goat populations are found in Asia and the Pacific (55.5\%) and Africa (32.9\%). Within Asia and the Pacific, the heaviest concentration of goats are found in China, India, Pakistan and Bangladesh which together account for $78 \%$ of the total population in this region. Within Africa, large populations of goats are found in Nigeria, Ethiopia, Somalia and Sudan, accounting for about $48 \%$ of the total population in the African continent. The total world population in 2007 was estimated at about 850 million goats of which 728 million were in low income food deficit countries (Daramola \& Adeloye, 2009).

Therefore, this study aims to determine coat colour distribution and identification of West African Dwarf goat in Abeokuta South (ABKS) and Abeokuta North (ABKN) Local Government Areas of Ogun State to determine the frequency of coat colour pattern of WAD goats.

\section{Materials and Methods}

\subsection{Sampling Site}

This study was carried out in ABKN and ABKS Local Government Areas of Ogun State, Nigeria. Eighteen (18) villages were sampled under the two Local Governments, 12 villages in ABKN Local Government and 6 villages in ABKS Local Government. ABKS LGAs has an area of $71 \mathrm{~km}^{2}$. It has a coordinates of $7^{\circ} 09^{\prime} \mathrm{N}, 3^{\circ} 21^{\prime} \mathrm{E}$. ABKN LGAs has an area of $808 \mathrm{~km}^{2}$. It has coordinates of $7^{\circ} 12^{\prime} \mathrm{N}, 3^{\circ} 12^{\prime} \mathrm{E}$. Most of the villages used for the study were populated by livelihood farmers under the supervision of the Ogun State Agricultural and Rural Development Programme (OGADEP) extension officers.

\subsection{Sampling Procedures}

Systematic sampling procedure was adopted for the study and participants were selected per household, more than $70 \%$ of approached farmers voluntarily participated in the sampling, and more than 40 farmers got interested and assisted in different locations sampled. Each location has a farm head which made it easier with extension agents for easy sampling with structured wooden farm pen. Ethical clearance was duly applied for and granted before the commencement of the study, hence, both the animals and participants' safety was ensured.

\subsection{Sample Size, Power, and Precision}

A total number of three thousand, three hundred and ten (3,310) WAD goats; 2511 doe and 799 bucks were sampled from 18 villages in ABKN and ABKS Local Government Areas.

\subsection{Measures and Covariates}

Some farmers were interviewed in order to know preference of coat colour selections, factors to consider in breeding and selections, challenges faced in goat production systems, prevalence disease and control measures adopted. Observations was done in sampling of various coat colour raised, tally system was used for easy data input, camera and coat colour chart was used for proper coat colour referencing. Training was done forassessors used for sampling collection for proper identification of different coat colour. No cultural beliefs were against different coat colour raised in the study areas.

\subsection{Research Design}

The experiment was subjected to natural occurrence with little or no manipulation of West African dwarf goats used.

The frequency of the recessive allele $\left(\mathrm{A}^{\mathrm{a}}\right)$ was estimated based on Hardy-Weinberg Principle (Falconer \& Mackay, 1996) as shown below: 


$$
\mathrm{q}=\sqrt{\frac{\mathrm{m}}{\mathrm{M}}}
$$

where, $\mathrm{q}=$ frequency of the recessive gene; $\mathrm{m}=$ observed number of animals exhibiting the recessive trait; $\mathrm{M}=$ total number of animals sampled.

The frequency of the dominant allele $\left(\mathrm{A}^{\mathrm{wt}}\right)$, $\mathrm{p}$ was obtained by subtracting $\mathrm{q}$ from one. The observed frequencies were tested against the expected Mendelian ratio of 3:1 corresponding to values of 0.75 for the dominant allele and 0.25 for the recessive allele using chi-square test. The null hypothesis $\left(\mathrm{H}^{\circ}\right)$ stated was that the population is in Mendelian proportion while the alternative hypothesis $\left(\mathrm{H}^{\mathrm{a}}\right)$ that the population is not in Mendelian proportion.

The result was input in Microsoft Excel sheet and Chi-Square Test of Goodness of fit was carried out to determine whether inheritance pattern of coat colour followed Mendelian proportion.

$$
\chi^{2}=\frac{\left.\sum \text { (Observed }- \text { Expected }\right)^{2}}{\text { Expected }}
$$

The level of significance of the test was examined at $\mathrm{P}=0.05$ and one degree of freedom $(\mathrm{DF}=1)$.

\section{Results}

The WAD goats are medium sized goats, coat colour is predominantly black and brown in both sex (Table 1), but animal with lateral stripes and swiss marking were less predominant in both LGA's (Table 2). Lateral stripes and swiss marking were the least predominant in Abeokuta North Local Government (Table 3), while lateral stripes and spotted brown were least predominant in Abeokuta South Local Government (Table 4). The black coat colour with black dominant type was commonly observed among the WAD goats reared in both local government Areas. The most common coat colour found in both local government areas was black followed by brown (Figures 1-3).

Table 1. Frequency of coat colour pattern of WAD goat identified in both Local Government Areas

\begin{tabular}{lllllll}
\hline Coat colour & Female & Male & Total & \% Female & \% Male & Total \\
\hline Black & 386 & 181 & 567 & 24.47 & 35.14 & 27.10 \\
Brown & 225 & 66 & 291 & 14.27 & 12.81 & 13.91 \\
Badgerface & 201 & 48 & 249 & 12.75 & 9.32 & 11.90 \\
Grey & 167 & 25 & 192 & 10.59 & 4.85 & 9.18 \\
Buckskin & 95 & 32 & 127 & 6.02 & 10.09 & 6.07 \\
Lateral belly & 96 & 23 & 119 & 6.09 & 4.46 & 5.69 \\
White and Black & 55 & 26 & 81 & 3.49 & 5.05 & 3.87 \\
White and brown & 89 & 16 & 105 & 5.64 & 3.10 & 5.02 \\
White and black marking & 38 & 9 & 47 & 2.41 & 1.75 & 2.25 \\
Black and white marking & 37 & 14 & 51 & 2.35 & 2.72 & 2.44 \\
Spotted white & 38 & 18 & 56 & 2.41 & 3.50 & 2.68 \\
Spotted black & 3 & 19 & 22 & 0.19 & 3.69 & 1.05 \\
Blackmash & 41 & 9 & 50 & 2.60 & 1.75 & 2.39 \\
Tan & 32 & 10 & 42 & 2.03 & 1.94 & 2.00 \\
White & 5 & 5 & 10 & 0.32 & 0.97 & 0.49 \\
Bezoar & 33 & 6 & 39 & 2.09 & 1.16 & 1.86 \\
Spotted brown & 20 & 5 & 25 & 1.27 & 0.97 & 1.19 \\
Lateral stripes & 10 & 3 & 13 & 0.63 & 0.58 & 0.62 \\
Swiss marking & 6 & 0 & 6 & 0.38 & 0.00 & 0.29 \\
Total & 1577 & 515 & 2092 & 100 & 100 & 100 \\
\hline
\end{tabular}


Table 2. Coat colour distribution of WAD goats in Abeokuta North and South LGAs

\begin{tabular}{llllllll}
\hline Coat colours & Predominant Genotype & Female & Male & Total & \% Female & \% Male & \% Total \\
\hline Black & Eumelanin & 652 & 289 & 941 & 37.48 & 36.17 & 28.42 \\
Brown & Eumelanin & 353 & 83 & 436 & 17.36 & 10.38 & 13.17 \\
Badgerface & Eumelanin & 282 & 64 & 346 & 13.78 & 8.01 & 10.45 \\
Grey & Eumelanin & 211 & 43 & 254 & 10.11 & 5.38 & 7.67 \\
Buckskin & Phaeomelanin & 179 & 43 & 222 & 8.84 & 5.38 & 6.70 \\
Lateral belly & Phaeomelanin & 116 & 38 & 154 & 6.13 & 4.76 & 4.65 \\
White and Black & Phaeomelanin & 113 & 36 & 149 & 5.93 & 4.50 & 4.50 \\
White and brown & Phaeomelanin & 101 & 33 & 134 & 5.33 & 4.13 & 4.05 \\
White and black marking & Phaeomelanin & 77 & 28 & 105 & 4.18 & 3.50 & 3.17 \\
Black and white marking & Eumelanin & 65 & 27 & 92 & 3.67 & 3.38 & 2.78 \\
Spotted white & Eumelanin & 64 & 24 & 88 & 3.50 & 3.00 & 2.66 \\
Spotted black & Eumelanin & 58 & 22 & 80 & 3.19 & 2.75 & 2.42 \\
Blackmash & Eumelanin & 49 & 14 & 63 & 2.51 & 1.75 & 1.90 \\
Tan & Phaeomelanin & 48 & 13 & 61 & 1.91 & 1.62 & 1.84 \\
White & Phaeomelanin & 46 & 11 & 57 & 1.83 & 1.37 & 1.72 \\
Bezoar & Eumelanin & 38 & 11 & 49 & 1.51 & 1.37 & 1.48 \\
Spotted brown & Eumelanin & 30 & 10 & 40 & 1.20 & 1.25 & 1.21 \\
Lateral stripes & Phaeomelanin & 23 & 10 & 33 & 0.92 & 1.25 & 1.00 \\
Swiss marking & Eumelanin & 6 & 0 & 6 & 0.24 & 0 & 0.18 \\
Peacock & Eumelanin & 0 & 0 & 0 & 0 & 0 & 0.00 \\
Total & & 799 & 3310 & 100 & 100 & 100 \\
\hline
\end{tabular}

The dominant coatcolour of WAD goat in both LGA's was black $(28.42 \%)$ followed by brown $(13.17 \%)$ followed bybadgerface (10.45\%) (Table 2).

Table 3. Frequency distribution of WAD goat in Abeokuta North Local Government Areas

\begin{tabular}{lllllll}
\hline Coat colour & Female & Male & Total & \% Female & \% Male & Total \\
\hline Black & 386 & 181 & 567 & 24.47 & 35.14 & 27.10 \\
Brown & 225 & 66 & 291 & 14.27 & 12.81 & 13.91 \\
Badgerface & 201 & 48 & 249 & 12.75 & 9.32 & 11.90 \\
Grey & 167 & 25 & 192 & 10.59 & 4.85 & 9.18 \\
Buckskin & 95 & 32 & 127 & 6.02 & 10.09 & 6.07 \\
Lateral belly & 96 & 23 & 119 & 6.09 & 4.46 & 5.69 \\
White and Black & 55 & 26 & 81 & 3.49 & 5.05 & 3.87 \\
White and brown & 89 & 16 & 105 & 5.64 & 3.10 & 5.02 \\
White and black marking & 38 & 9 & 47 & 2.41 & 1.75 & 2.25 \\
Black and white marking & 37 & 14 & 51 & 2.35 & 2.72 & 2.44 \\
Spotted white & 38 & 18 & 56 & 2.41 & 3.50 & 2.68 \\
Spotted black & 3 & 19 & 22 & 0.19 & 3.69 & 1.05 \\
Blackmash & 41 & 9 & 50 & 2.60 & 1.75 & 2.39 \\
Tan & 32 & 10 & 42 & 2.03 & 1.94 & 2.00 \\
White & 5 & 5 & 10 & 0.32 & 0.97 & 0.49 \\
Bezoar & 33 & 6 & 39 & 2.09 & 1.16 & 1.86 \\
Spotted brown & 20 & 5 & 25 & 1.27 & 0.97 & 1.19 \\
Lateral stripes & 10 & 3 & 13 & 0.63 & 0.58 & 0.62 \\
Swiss marking & 6 & 0 & 6 & 0.38 & 0.00 & 0.29 \\
Total & 1577 & 515 & 2092 & 100 & 100 & 100 \\
\hline
\end{tabular}


Table 4. Frequency distribution of WAD goat in ABKS Local Government Area

\begin{tabular}{lllllll}
\hline Coat colour & Female & Male & Total & \% Male & \% Female & Total \\
\hline Black & 266 & 108 & 374 & 38.03 & 28.48 & 30.71 \\
Brown & 128 & 17 & 145 & 5.99 & 13.70 & 11.90 \\
Badgerface & 81 & 16 & 97 & 5.63 & 8.67 & 7.96 \\
Grey & 44 & 18 & 62 & 6.34 & 4.71 & 5.09 \\
Buckskin & 84 & 11 & 95 & 3.87 & 8.99 & 7.79 \\
White and black & 58 & 10 & 68 & 3.52 & 6.21 & 5.58 \\
Lateral belly & 20 & 15 & 35 & 5.28 & 2.14 & 2.87 \\
White and Brown & 12 & 17 & 29 & 5.99 & 1.28 & 2.38 \\
White and Black marking & 39 & 19 & 58 & 6.69 & 4.18 & 4.76 \\
Spotted white & 26 & 6 & 32 & 2.11 & 2.78 & 2.62 \\
Spotted black & 55 & 3 & 58 & 1.06 & 5.89 & 4.76 \\
Black and white marking & 28 & 13 & 41 & 4.58 & 2.99 & 3.37 \\
Tan & 16 & 3 & 19 & 1.06 & 1.71 & 1.56 \\
White & 41 & 6 & 47 & 2.11 & 4.39 & 3.86 \\
Bezoar & 5 & 5 & 10 & 1.76 & 0.53 & 0.82 \\
Blackmash & 8 & 5 & 13 & 1.76 & 0.86 & 1.07 \\
Lateral stripes & 13 & 7 & 20 & 2.46 & 1.39 & 1.64 \\
Spotted brown & 10 & 5 & 15 & 1.76 & 1.07 & 1.23 \\
Total & 934 & 284 & 1218 & 100 & 100 & 100 \\
\hline
\end{tabular}

Table 5. Gene frequencies of coat colour in West African dwarf goat

\begin{tabular}{lllll}
\hline Coat colour & Observed frequency & Expected frequency & Gene frequency & $\chi^{2}$ test \\
\hline Phaeomelanin standard pigmentation & 1003 & 827.5 & 0.30 & $*$ \\
Eumelanin standard pigmentation & 2307 & 2482.5 & 0.70 & $*$ \\
\hline
\end{tabular}

Note. Significant * $\mathrm{P}<0.05$.

\subsection{Gene Frequencies of the Coat Colour}

The gene frequencies were shown in Table 5 with the level of phaeomelanin standard pigmentation and eumelanin standard pigmentation 0.30 and 0.70 respectively.

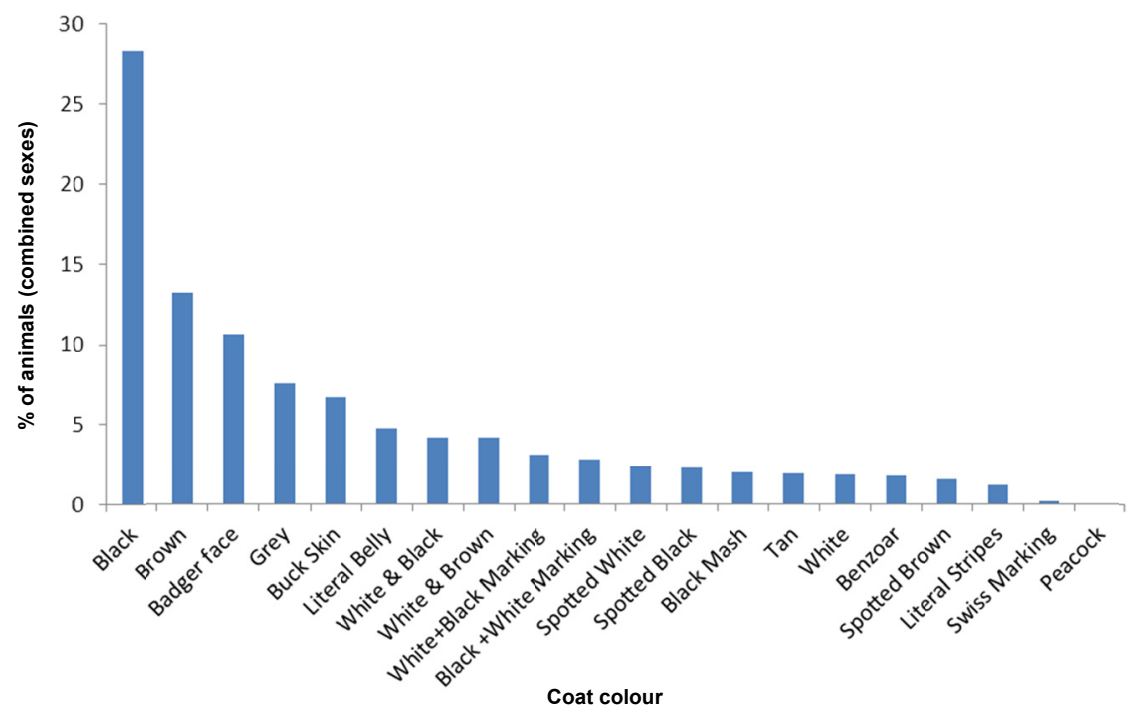

Figure 1. Coat colour distribution of WAD goat in Abeokuta North and South Local Government Areas (combined sexes) 
